DOI: 10.24275/uama.5821.7598

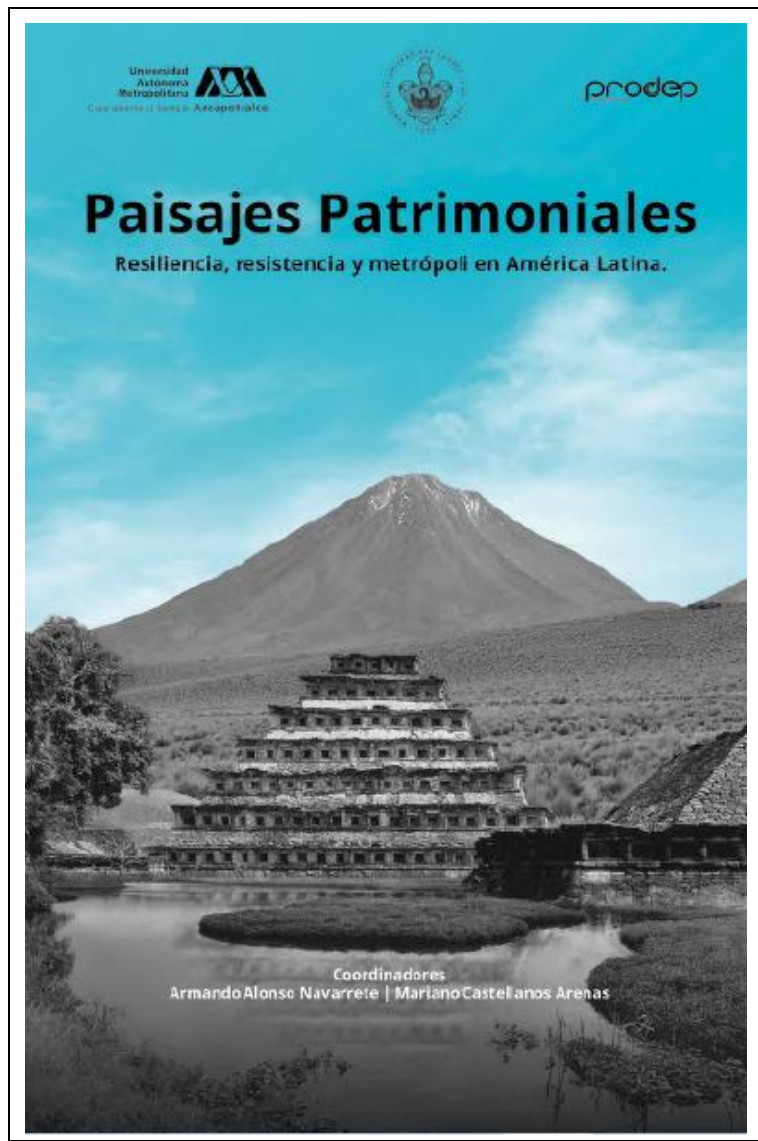

Castellanos Arenas, Mariano (2020).

ORCID: 0000-0002-1790-4888

El paisaje del agua como vertebrador del patrimonio industrial en el Valle de Atlixco, Puebla.

p. $154-179$

En:

Paisajes patrimoniales. Resiliencia, resistencia y metrópoli en América Latina. IV. Paisajes del agua / Armando Alonso Navarrete y Mariano Castellanos Arenas, coordinadores. Ciudad de México: Universidad Autónoma Metropolitana, Unidad Azcapotzalco, 2020.

Fuente: ISBN 978-607-28-1996-2 (versión electrónica).

Relación: http://hdl.handle.net/11191/7575

\begin{tabular}{|c|c|c|}
\hline $\begin{array}{c}\begin{array}{r}\text { Universidad } \\
\text { Autónoma } \\
\text { Metropolitana }\end{array} \\
\text { Casa abierta al tiempo Azcapotzalco } \\
\text { Universidad Autónoma Metropolitana } \\
\text { Unidad Azcapotzalco } \\
\text { https://www.azc.uam.mx/ }\end{array}$ & $\begin{array}{l}\begin{array}{r}\text { División de Ciencias y Artes para } \\
\text { el Diseño }\end{array} \\
\text { https://www.cyad.online/uam/ }\end{array}$ & $\begin{array}{l}\begin{array}{l}\text { Departamento del Medio } \\
\text { Ambiente }\end{array} \\
\text { http://www.medioambiente.azc } \\
\text {.uam.mx/jefatura.html }\end{array}$ \\
\hline & $\begin{array}{c}\text { Área de Investigación } \\
\text { Arquitectura del Paisaje } \\
\text { Área de Investigación } \\
\text { Arquitectura del Paisaje }\end{array}$ & \\
\hline
\end{tabular}

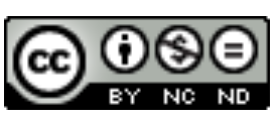

Excepto si se señala otra cosa, la licencia del ítem se describe como

Atribución-NoComercial-SinDerivadas

https://creativecommons.org/licenses/by-nc-nd/4.0/

D.R. C 2020. Universidad Autónoma Metropolitana, Unidad Azcapotzalco, División de Ciencias y Artes para el Diseño, Departamento del Medio Ambiente, Área de Investigación Arquitectura de Paisaje. Se autoriza copiar y redistribuir el material en cualquier medio o formato, siempre y cuando se den los créditos de manera adecuada, no puede hacer uso del material con propósitos comerciales, si remezcla, transforma o crea a partir del material, no podrá distribuir el material modificado. Para cualquier otro uso, se requiere autorización expresa del titular de los derechos patrimoniales. 


\title{
El paisaje del agua como vertebrador del patrimonio industrial en el Valle de Atlixco, Puebla.
}

\author{
Mariano Castellanos Arenas \\ Benemérita Universidad Autónoma de Puebla. \\ castellanos.arenas@gmail.com
}

Resumen: Este es un trabajo sobre la patrimonialización de un paisaje cuya estructura está conformada por las instalaciones hidráulicas situadas a lo largo del Río Cantarranas, en el Valle de Atlixco. Es decir, el agua que corre por este río es el eje vertebrador de todo un conjunto de bienes culturales de carácter rural, urbano e industrial de primer orden, que tiene como antecedentes históricos el periodo prehispánico; sin embargo, para este capítulo solo abordaré el paisaje del agua entre 1898-1928 y su relación con las fábricas textiles. Asimismo, desde la perspectiva de los estudios del patrimonio se considera que el territorio ha sido modelado por el uso del agua, en cuya configuración encontramos un rico patrimonio industrial. En este sentido, el objetivo de este análisis es develar sistemáticamente cómo se estructura el paisaje industrial en el valle y al tiempo que se analiza la distribución del líquido, los aprovechamientos, la fuerza motriz y los volúmenes que se necesitaron para hacer funcionar a cada una de las seis factorías localizadas en el valle. Para concluir, se trata de hacer una reflexión sobre la importancia del agua en Atlixco como el elemento vertebrador del paisaje y este como un patrimonio común.

Palabras clave: paisaje del agua, patrimonio industrial, instalaciones hidráulicas, fábricas textiles.

Abstract: This paper talks about the heritage valuation of a landscape whose structure is conformed by the hydraulic installations located along the Cantarranas River, in the Atlixco Valley. In other words, the water that runs through this river is the backbone of a whole set of first-rate rural, urban and industrial cultural assets, whose historical background is the pre-Hispanic period; however, for this chapter I will only address the landscape of water that existed between the years1898 -1928 and its relationship with textile factories in the area. Likewise, from the perspective of heritage studies, it is considered that this territory has been shaped by the use of water, in whose configuration we find a rich industrial heritage. In this sense, the objective of this analysis is to systematically reveal how the industrial landscape in the valley is structured and at the same time to analyze the distribution of water, its differente uses, its driving force and the water volumes that were needed to make each one of the six factories located in the valley work. To conclude, it is about realizing the importance of water in Atlixco as the backbone of the landscape and as a common heritage.

Keywords: Waterscape, industrial heritage, hydraulic system, textile factories. 


\section{Introducción.}

El estudio de la industria textil en Puebla es fundamental para comprender el desarrollo económico de esta entidad, sobre todo entre los siglos XIX y XX. Particularmente, para el Valle de Atlixco, encontramos investigaciones acerca de la industria, el sindicalismo, la cultura obrera y los empresarios, como el ya clásico libro de Jan Bazant, Evolución de la industria textil poblana (1544-1845) de 1964; el de Leticia Gamboa y Rosalina Estrada, Empresas y Empresarios textiles de Puebla, Análisis de dos casos, de 1986; el de Samuel Malpica, Atlixco: historia de la clase obrera, de 1989; el de Cristina Gómez, Puebla: lo obreros textiles en la revolución, del mismo año, o el de Leticia Gamboa, La urdimbre y la trama. Historia social de los obreros textiles de Atlixco (1899-1924), de 2001. Aún cuando existe una amplia bibliografía al respecto, poco se ha abordado el tema del agua como el protagonista en la configuración del paisaje y como el elemento configurador del patrimonio industrial en este valle.

Es importante destacar que sobre el agua y la industria en Atlixco, tenemos los trabajos de Juan Carlos Garavaglia, Atlixco: el agua, los hombres y la tierra en un valle mexicano (siglos XIV-XVII), de1996, o el de Rocío Castañeda, Las aguas de Atlixco. Estado, haciendas, fábricas y pueblos, 18801920, del 2005; además el trabajo de quien escribe estas líneas, El Agua, la energía y la producción textil en la fábrica de Metepec, 1898-1908, de 2009. ${ }^{1}$ Por esta razón se considera pertinente continuar el abordaje sobre el agua, pero ahora desde un nuevo enfoque donde el líquido es la matriz que ha concebido un paisaje que está caracterizado por el patrimonio industrial más importante de la región.

Ahora bien, este trabajo trata sobre las instalaciones hidráulicas al servicio de las fábricas textiles situadas en torno del Río Cantarranas, entre la segunda mitad el siglo XIX y la primera mitad del XX. Sobre este paisaje del agua como el vertebrador de toda una sucesión de unidades productivas, hoy consideradas patrimonio industrial. Cabe decir, que el sistema hidráulico del Río Cantarranas, está compuesto por 6 manantiales $\mathrm{u}$ ojos de agua, los cuales abastecen al río y eran aprovechadas por 1 ciudad y 6 pueblos; además de que hacía funcionar a 10 haciendas, 11 ranchos y 1 molino de trigo; al mismo tiempo a 6 plantas hidroeléctricas y 6 fábricas textiles, consideradas éstas como pequeñas unidades de paisaje dentro de uno más grande, que es el valle de Atlixco. La infraestructura total estaba constituida por diecisiete presas derivadoras, cincuenta canales, siete tuberías, un acueducto elevado, diecisiete vasos de depósito naturales y artificiales y dos tanques de reposo; elementos nodales del sistema hidráulico.

1 Véase en el apartado de fuentes la bibliografía de los autores citados. 
Todo este sistema era soportado por las derivaciones, que son presas en las que se instalaron tomas con la finalidad de ser aprovechadas por parte de aquellas unidades. Es muy importante aclarar que aquí sólo se realizará un análisis del territorio formado por el complejo hidríco-indusrial. Es decir, sólo me referiré aquí al uso del agua por las fábricas. El objetivo es mostrar cuál era la capacidad de la infraestructura hidráulica para hacer uso del líquido del que se disponían y el volumen que permitía generar la fuerza que se requería para mover cada una de las fábricas. La idea es la valoración como proceso de convención hacia la patrimonialización y reflexionar sobre la configuración del territorio para resignificar este patrimonio desde la mirada del paisaje del agua.

Para ello, es necesario comprender cómo el agua es y ha sido el elemento configurador del paisaje a lo largo de la historia. El líquido como el modelador de las áreas vitales, de los asentamientos humanos, de sus caminos y de casi todas sus actividades. Es decir, todas las trazas dejadas por el agua son los ejes ordenadores del mundo, son los símbolos del nacimiento perpetuo y su cauce sinónimo del pasar de la vida. En este sentido, es importante resaltar que el agua es el factor determinante que define y que ha definido la historia de todas las sociedades en el planeta.

En muchas culturas el agua es parte fundamental de su origen. En el lejano Oriente existe una relación directa con el paisaje, desde la bruma hasta los ríos, que contiene un profundo sentido espiritual. En el cristianismo, por ejemplo, es entendida como purificadora: lavar el cuerpo del pecado. En el Génesis, de la Biblia, se dice que "al comienzo Dios creo los cielos y la tierra", "creo el firmamento y separó las aguas"; sin embargo, las aguas del Génesis son pasivas en donde sólo un Dios actúa, a diferencia de la mitología griega. Lo griegos pensaban que el Dios Océano es como el padre de los dioses que encarna el "poder generador de todos los seres". Las aguas primordiales son dadoras de energía y están representadas en la pareja de Océano y Thetys, portadores de la dualidad de lo masculino y lo femenino (Tortolero; 2006: 20).

En el México antiguo Tlaloc fue el dios azteca del agua y señor del trueno. Representaba la fertilidad y la abundancia de las cosechas. Su morada era el mundo subacuático denominado Tlalocan y es a este reino a donde iban a dar los espíritus de todos los seres humanos que morían por causas relacionadas con el agua y los truenos. En el relato cosmogónico de Tlaloc se narra que allí todo era abundancia y por supuesto no faltan los brotes de maíz, (el alimento básico), ni las frutas más frescas. Se creía que Tlaloc habitaba en el Altepet/ y su personalidad se confundía en él, ya que se creía que fue desde ahí que creaba la lluvia. El Altepetl fue considerado como un recipiente que se hallaba repleto de agua y que en épocas de Iluvia la 
liberaban, mientras que durante la sequía la retenían. En náhuatl se utiliza el vocablo atl-tépetl para designar "agua-montaña" (Oliver; 2009: 40-43).

En el Tlalocan la bella Xochiquétzal era la esposa del viejo dios del agua, pero ésta fue robada por Tezcatlipoca dios del cielo y de la tierra: fuente de vida, tutela y amparo del hombre, origen del poder y la felicidad, dueño de las batallas; omnipresente, fuerte e invisible. Ante esta situación Tlaloc se unió a Chalchiuhtlicue, la diosa del amor y el agua dulce que brotaba del interior de la tierra; es decir, diosa de los manantiales. Ellos engendraron dos hijos, los tlalocas (las nubes): Huixtocihuatl y Tlaloques que marcaban las cuatro esquinas del universo y sostenían cuatro vasijas de barro desde los cuales dejaban caer cuatro formas de aguas sobre la tierra: la lluvia, el granizo, el agua sucia y la sequía (Oliver; 2009: 40-43).

El Altepetl además de ser agua y montaña, también fue el término para referirse al "pueblo" o también "señorio", término que es entendido como el lugar desde donde se gobierna una región (Fernández y García; 2006: 16). Esta es una forma de Tlaloc, que puede verse representada en el Valle de Atlixco coronado por el volcán Popocatépetl, es decir, por la montaña que gobierna y de cuyos glaciares riega las tierras del valle, como el dador de las aguas. El nombre del volcán significa en náhuatl "humo-montaña" o monte que humea que viene de popoca-tepetl. Ahora bien, Atlixco, significa atl, ixtlatl y co, cuya traducción literal sería "aguavalle-lugar", lo que significa: "lugar del valle de agua" (Diccionario Náhuatl; https://aulex.org/nah-es/).

Esto nos permite comprender que desde su origen geológico y cosmogónico el Valle de Atlixco es un lugar de agua. En la idea de su territorialidad estructurada por el líquido subyace el concepto de paisaje. De igual manera, para comprender su estructura, tanto de su pasado como de su presente, es necesario conjugar territorio y agua en una sola noción: paisaje del agua. Es decir, el Valle de Atlixco como paisajes del agua tiene un origen mitológico, histórico, geográfico y cultural.

Jacques Bethemont, Anne Rivière-Honegger y Yves Francois Le Lay plantean la disyuntiva que existe entre "el agua en los paisajes" y "los paisajes del agua", ya que el agua desempeña un papel protagónico que condiciona al resto de los elementos configuradores del paisaje, así como en su funcionamiento y la dinámica en la percepción social y cultural del territorio (Citado por Mata y Fernández; 2008: 3). No podemos concebir la vida sin el agua, de la misma manera que no se puede pensar en el desarrollo industrial sin este vital elemento. Luego entonces, debemos considerar que estos paisajes son del agua pero también con agua, ya que son un producto resultante y perceptible de la combinación dinámica de elementos físicos (entre los cuales el agua es relevante) con elementos 
antrópicos (la acción humana); combinación que convierte al conjunto en un entramado social y cultural en continua transformación.

Conceptualmente los principales elementos que definen a estos paisajes son el mar, los ríos, los torrentes, las ramblas, los humedales, los estanques, los deltas, lagos y lagunas. Esto siempre en relación con aquellos otros elementos que denotan la permanencia histórica de las relaciones entre la sociedad y el líquido, como las presas, los puentes, las acequias, las huertas, los molinos, las fachadas fluviales de las ciudades, los caminos, los canales agrícolas o industriales.

Ahora, el paisaje del agua como patrimonio cultural tiene el mismo valor que sus componentes, en concreto los hidráulico-industriales, así como las instalaciones y/o construcciones propias para producción textil. Al mismo tiempo, son los elementos configuradores del patrimonio cultural, que adquieren todo un sentido interpretativo y un valor especifico como componentes del paisaje en el Valle de Atlixco, son como dice de David Lowenthal el "patrimonio de patrimonios" (1996: 245-241).

En este sentido, podemos encontrar en todo el mundo ejemplos magníficos de las relaciones entre sociedad y agua, como las creadoras de un conjunto de paisajes de elevado valor patrimonial, pero también ecológico, económico o simbólico, cada vez más apreciados y utilizados bienes públicos. Por eso, cabe decir que, es importante superar la separación entre los dos conceptos, agua por una parte y sociedad por la otra, y optar por una nueva integración de ambos. Una integración sociedad/agua que pueda ser útil para construir una nueva actitud social hacia este tipo de paisajes y por supuesto a cualquier otro.

Finalmente, es importante aclarar que este trabajo es parte de una investigación más amplia y en proceso que aborda todo el complejo hidráulico del Valle de Atlixco. Se trata de un estudio soportado en un minucioso trabajo de campo y una sistemática investigación documental. Este trabajo está dividido en dos grandes apartados y una conclusión. El primero está constituido por un contexto histórico y territorial, el valle de Atlixco entre el siglo XIX y el XX, más precisamente entre los años1898 y 1928. Periodo que inicia con la creación de la Comisión Nacional del Agua y el proyecto del sistema hidráulico para la Fábrica de Metepec. Hay que aclarar que Metepec fue el último proyecto de infraestructura industrial en el valle, pero la primera unidad productiva en aprovechar las aguas del río. Esta situación provocó un cambio radical, tanto en los volúmenes utilizados aguas abajo como en la configuración actual del paisaje. El periodo termina, con el Estudio de Reglamentación para el uso del agua del río Cantarranas del Valle de Atlixco, realizado por la Secretaría de Agricultura y Fomento de la República Mexicana, del Archivo Histórico del Museo 
Industrial de Metepec, en el Fondo Documental Compañía Industrial de Atlixco S. A, en la Sección Departamento Jurídico, Serie Distribución de Agua. Podemos asegurar que es en este periodo que se configura el paisaje del agua que hoy se presenta.

El segundo apartado, es el análisis del paisaje del agua, a partir del río como la columna vertebral que une a todos los bienes culturales y que forma un gran patrimonio industrial. Este apartado está basado en dos documentos: el Informe relativo al Estudio de Reglamentación hecha por VI Zona de Puebla a los Ríos Cantarranas, Tianguismanalco y Manantiales de Axocopan de la Secretaría de Agricultura y Fomento (SAF), de la República Mexicana, Delegación de Aguas, Tierras y Colonización, Departamento Sur, ubicado en la Sección del Fondo Aprovechamientos Superficiales del Archivo Histórico del Agua (AHA-Conagua). Así mismo, del Esquema de Distribución de Aguas del Rio Cantarranas, Edo. de Puebla, desde su nacimiento hasta su confluencia con el rio Nexapa, de la SAF, VII Zona, localizado en el Archivo Histórico del Museo Industrial de Metepec, en el Fondo Documental Compañía Industrial de Atlixco S. A, en la Sección Departamento Jurídico, Serie Distribución de Agua.

Se concluye con la reflexión sobre el reconocimiento de los usos del agua en la historia, como uno de los elementos que hacen del paisaje un patrimonio cultural de primer orden. La configuración del territorio modelado por el agua, otro de los factores que lo dotan de carácter. En este sentido, pensar en el agua desde el presente como un bien cultural y como recurso natural no renovable, es fundamental para la construcción o fortalecimiento de la identidad. Así mismo permitirá una la lectura prospectiva del paisaje del agua que puede coadyuvar en los planes futuros para uso racional del líquido y para que la sociedad lo asuma como un bien cultural común.

\section{El paisaje del agua en el valle de Atlixco.}

El valle de Atlixco es una región natural del Estado de Puebla con una extensión de 3, $074000 \mathrm{~m}^{2}$. $^{2}$ Se localiza a unos 40 kilómetros al suroeste de la capital del estado, en las inmediaciones de la Sierra Nevada. El valle es caracterizado por su clima templado, con lluvias moderadas y suelos fértiles, que son regados por las aguas de los ríos irrigados por los glaciares que están en las cumbres del volcán Popocatépetl. Entre estos ríos se encuentra el Río Cantarranas. Cabe destacar, que debido a la intensa actividad humana en la zona, el valle ha perdido sus ecosistemas nativos, y en su lugar, la planicie está cubierta por cultivos, especialmente de gramíneas, cereales y flores.

2 Localización del Valle de Atlixco, Estado de Puebla, Republica Mexicana. Coordenadas: $8^{\circ} 54^{\prime} 45^{\prime \prime} \mathrm{N}, 98^{\circ} 25^{\prime} 40^{\prime \prime} \mathrm{O}$. 
El volcán Popocatépetl también es conocido por los lugareños como el Popo o Don Goyo. Es un volcán activo en forma cónica simétrica que bordea parte el valle y está unido por la parte norte con el Iztaccíhuatl mediante un paso montañoso conocido como Paso de Cortés. El Popo es el segundo volcán más alto de México, con una altitud máxima de 5,500 metros sobre el nivel del mar, con un diámetro de $25 \mathrm{~km}$ en su base y la cima es el corte elíptico de un cono, con una orientación noreste-suroeste. La distancia entre las paredes de su cráter varía entre los 660 y los $840 \mathrm{~m}$. Los estudios paleomagnéticos indican que tiene una edad aproximada de 730,000 años. (Chávez y Trigo, 2009, p. 13).

Los glaciares perennes del volcán están cerca de la boca del cono, en la punta de la montaña con 17 millones de metros cúbicos. Por debajo de los 4,000 m. los arroyos adquieren velocidad y volumen y los manantiales son más frecuentes y abundantes. Por otra parte, por debajo de los 3,500 m. las aguas ejercen una fuerte erosión en el terreno ya que su caudal depende de los deshielos y las precipitaciones. A esta altura el agua se encuentra bien oxigenada, suave y baja en sólidos totales (Reyes y Shánchez; 2004: 81-82).

En general los suelos que predominan en las zonas altas son de baja calidad agrícola y sus rendimientos son limitados, debido sobre todo a su composición, principalmente de arena que es mayor al $50 \%$. Los suelos a partir de los 2200 al nivel del mar, han sido clasificados como regosoles eutricos y foezem lúvico. Los primeros son suelos poco desarrollados, de material inconsistente y de origen aluvial, los segundos son suelos jóvenes, poco desarrollados, que se distinguen por presentar en el subsuelo una capa que parece roca, mientras que en la superficie ofrecen acumulaciones de arcilla, carbonato de calcio, fierro y manganeso. Luego se tienen los foezem háplico con una capa superficial oscura, rica en materiales orgánicos y nutrimentos, pero su grosor varía en los terrenos situados en laderas y pendiente, en donde su productividad agrícola ha sido baja. A este nivel se encuentra un predominio de suelos clasificados como regosoles que generan bajos rendimientos agrícolas (Reyes y Sánchez; 2004: 92).

Tierras más abajo, en el territorio que ocupa Atlixco, se formaron diferentes tipos de fluvisoles, cuyo componente es el limo, que cubrieron con el paso del tiempo los suelos ranker de origen volcánico. La capa de ranker representa una ventaja, pues permite la conservación del agua en las capas superiores, con suelos propicios para la agricultura. Esto se debe a que los suelos son más ligeros y al mismo tiempo con una capa de tierra arable más profunda, hasta dos metros en la misma parte central del Valle de Atlixco.

La temperatura media anual es de $18^{\circ} \mathrm{C}$ y con una precipitación suficiente que le ha permitido obtener cosechas aún en cultivos de temporal, así como 
recargar sus acuíferos todo el año; por su evapostranspiración, no sería capaz de soportar exportaciones constantes de sus recursos acuíferos, por cuanto no recibe una alta precipitación anual. El valle se encuentra prácticamente irrigado en su totalidad gracias a innumerables derivaciones y canales construidos desde la época prehispánica. El sistema de riego, que se alimenta de los glaciares del Popocatépetl, se complementa con la temporada de lluvias que inicia regularmente entre abril y mayo, para terminar en octubre. El número promedio de días de lluvia al año fluctúa entre los 80 y los 100 (Reyes y Sánchez; 2004: 130).

Gracias a esta abundancia de agua y a la fertilidad de las tierras, durante el siglo XVI, el valle fue denominado por Motolinía (franciscano fundador de la ciudad de Puebla) como "Val de Cristo"3 y se convirtió rápidamente en un importante asentamiento español y parte considerable de las tierras fertiles pasaron a formar parte de propiedades privadas, quedando integradas a las haciendas, los ranchos, los molinos y posteriormente a las fábricas y plantas hidroeléctricas. En 1574, Alonso Díaz de Carrión (fundador de la ciudad de Atlixco) pidió al virrey Martín Enríquez su acuerdo para la fundación de una villa independiente de la jurisdicción de la ciudad de Puebla. Finalmente, por cédula real se dio al nuevo emplazamiento el título de Villa de Carrión (hoy Atlixco), concediéndole su escudo de armas. Más tarde, por otro decreto, el 14 de febrero de 1843 la Villa de Carrión fue elevada a la categoría de ciudad (Garabaglia; 1996: 72-72).

Esta villa se convirtió en el centro productor de cereales más importante de la Nueva España y abasteció a casi todo el reino, incluso después de la Independencia de México, en el siglo XIX, siguió siendo un importante productor. Este auge agrícola, además de atraer a gran numero de nuevos pobladores, atrajo a las órdenes religiosas, de modo que para 1585 ya se estaba fundando el convento de San Agustín, en 1612 el de la Merced y posteriormente el de los Carmelitas. Para 1624 también se fundó el convento de Santa Clara y se estableció el Hospital de San Juan de Dios y otras instituciones, que por cierto, todos estos también forman parte

3 Alrededor del año 1400, el espacio que hoy conocemos como Valle de Atlixco, era un área de frontera y de conflicto entre varios señoríos y diversas etnias: sobre las faldas del volcán tenemos a Ocopatlayucan/Tochimilco, resultado de una colonia xochimilca que emigro hacia el Este; señorío ligado a los tenochcas, es decir a la Triple Alianza del Vallde de México. También tenemos a Quauhquechollan (o Huaquechula), señorío independiente, que en sus inicios ocupó lo que ahora es el municipio de Atlixco. En 1403, los huaquecholtecas, atacaron a sus vecinos los Huexotzincas y Calpanecas y al repeler ese ataque, los huaquecholtecas son obligados a ubicarse más abajo. Huexotzingo y Calpan fueron señoríos de doble liderazgo sobre los poblados que se ubicaron en las faldas de los cerros y la entrada al valle, como San Pedro Atlixco, Tianquizmanalco (hoy San Martín) y Coyula, correspondían al señorío de Huexotzigo y Atlimeyaya, el otro Tianquizmanalco (hoy San Juan), Cuaco y Axocopan, pertenecían a Calpan. Desde mediados del siglo XVI, durante la conquista de México, el valle y gran parte del altiplano central, fue encomendado a los franciscanos para su evangelización. (Garabaglia; 1996: 72-72) (Paredes; 1991: 22). 
de un importante patrimonio cultural en la región. (Catálogo Nacional de Monumentos Históricos Inmuebles; 1988; 9).

En cuanto a los territorios ocupados para el cultivo, éstos estuvieron distribuidos al costado de los ríos Cantarranas y Nexapa. Cabe destacar que desde aquellas épocas estos terrenos han sido de los más codiciados, tanto por la calidad de los suelos como por su disponibilidad de agua. Por esta razón, la mayor concentración de tierras de cultivo eran de las haciendas, los ranchos y las fábricas textiles, que fue especialmente notable en torno al río Cantarranas. De esta manera, la mayor parte de las tierras altas, menos fértiles, de temporal y sin agua de riego, quedaron en manos de los pueblos (Luna, 2011;100).

Es necesario hacer hincapié, que los españoles que llegaron a Atlixco después de la Conquista y durante la Colonia mantuvieron las obras de riego existentes, construidas por los pueblos originarios, pero conforme la actividad agrícola e industrial se fue incrementando y la población creciendo, tuvieron que ampliarlas y modificarlas para multiplicar las tomas de agua. Por ello construyeron cajas partidoras, canales generales y secundarios, para la distribución del líquido entre los múltiples usuarios, lo que también obligó a la generación de los primeros repartos. Entre 1592 y 1594, Baltasar de Herrera y Arévalo, comisionado por el virrey Juan de Velasco, repartió las aguas del río Cantarranas y se permitió que por primera vez se midiera el flujo de las aguas. Asimismo, se establecieron normas y reglas con la finalidad de evitar y resolver conflictos por el recurso los cuales estuvieron vigentes hasta la creación de los primeros reglamentos a finales del siglo XIX. (Castañeda, 2005, 73).

Durante los siglos XVI y XIX el agua de los ríos fue controlada en su totalidad por las haciendas y los ranchos, para producir principalmente trigo, y luego las fábricas para la producción de textiles de algodón. Después de estas unidades productivas, las aguas eran distribuidas a los pueblos y la ciudad de Atlixco para servicio doméstico y uso público. (Mertens; 1983: 17). Luego, durante el Porfiriato (1876-1910), estas unidades fueron los elementos socioeconómicos esenciales para impulsar el crecimiento, la modernización y desarrollo de México. Es importante hacer mención que el grado de dependencia de las haciendas y las fábricas con respecto al mercado provocó un sistema laboral de explotación del campesino y el obrero. Situación que originó la posterior Revolución Mexicana y el movimiento obrero respectivamente. En este sentido, el agua resultó ser uno de los recursos naturales estratégicos para la consecución de las metas económicas del régimen. La exigencia hidráulica más importante se dio en la expansión industrial porfiriana, que provino de la demanda energética de nuevo tipo. (Castañeda; 2001: 124-186). 
En este periodo, de manera paralela al desarrollo de la hacienda y de la industria textil alcanzó un notable desarrollo, tanto, que Atlixco se convirtió en un polo de atracción para instalación de infraestructura fabril, la cual comenzó a aprovechar la energía hidráulica generada por el río. Simultáneamente, se construyó el ferrocarril entre la ciudad de Puebla y Atlixco, y luego de ésta a la Ciudad de México, lo que permitió estrechar el vínculo económico entre las poblaciones, al tiempo que las comunicó con la capital del país.

En el caso de los emplazamientos industriales en esta región, nacieron lejos de las urbes en forma de molinos buscando el líquido que les sirviera para producir energía. Casi como una norma, primero aparecieron los molinos y posteriormente las ruedas hidráulicas al servicio de una hilatura. Las construcciones industriales y las instalaciones necesarias para su funcionamiento implicaron cambios radicales en el uso de los recursos naturales como el agua, los bosques y la tierra, pues se levantaron edificios para albergar la maquinaria, caseríos para los trabajadores, tendido de vías férreas y por supuesto se construyeron complejos sistemas hidráulicos. Las consecuencias de este proceso fueron no sólo económicas y sociales, sino una transformación total en el paisaje.

A mediados del siglo XIX la producción de trigo llevó a consolidar al molino de San Mateo, el más grande de la región. Paralelamente la industria textil alcanzó un notable desarrollo, instalándose las fábricas La Concepción y La Carolina, las cuales empezaron a aprovechar la energía hidráulica generada y a finales de esa centuria, en 1889, se inauguró el Ferrocarril Interoceánico entre Puebla y Atlixco, que estrechó el vínculo económico, al tiempo que las comunicó con la capital del país. En 1899 se inauguró la fábrica textil El León y poco tiempo después El Carmen, El Volcán y, en 1902, la gran fábrica de Metepec (Catalogo Nacional de Monumentos Históricos Inmuebles; 1988; 10).

Se ha de decir que no fue casual que esta región se volviera un importante imán, en primer lugar, porque parecía contar con una potencial oferta de mano de obra que suponía una población numerosa y en segundo lugar, por la abundancia y calidad del agua, que fue el elemento fundamental. Los antiguos pobladores, los terratenientes europeos y los empresarios, en su mayoría extranjeros, fueron siguiendo el curso del agua que se aprovechó para la agricultura, para la generación de fuerza motriz al servicio de la producción textil y luego para la generación de electricidad. Finalmente, todos los sitios antes mencionados, hoy con sus instalaciones deterioradas en la mayoría de los casos, configuran el patrimonio cultural de la región, el cual está articulado por el agua. 


\section{El paisaje del agua como vertebrador del patrimonio industrial.}

Este apartado esta basado en el Estudio de Reglamentación hecha por VI Zona de Puebla a los Ríos Cantarranas, Tianguismanalco y Manantiales de Axocopan de la Secretaría de Agricultura y Fomento (SAF), de la República Mexicana, Delegación de Aguas, Tierras y Colonización, Departamento Sur (Archivo Histórico del Agua; Aprovechamientos Superficiales; 4314; 57493; 1928; pp. 1-320). Es un documento que contiene información científica, técnica administrativa, política y territorial, del cual sólo se recogió la información relacionada a la industrial para realizar el análisis general del río Cantarranas y sus aprovechamientos a partir de las derivaciones: la cantidad por metro cúbico anual, litros por segundo y la energía generada de cada una de las seis fábricas textiles instaladas en los márgenes del río. La idea es demostrar que el caudal de agua es la columna vertebral que articula el patrimonio industrial del valle de Atlixco. Podemos afirmar que el paisaje del agua es también un bien cultural que hoy se conserva casi en su totalidad. En algunos casos hay elementos que se encuentran en la ruina por el desuso, el abandono y las inclemencias del tiempo y en otros en perfecto estado y funcionamiento.

Es importante decir que el paisaje del agua en el Valle de Atlixco inicia con la formación de varios talwegs ${ }^{4}$ en el volcán Popocatepetl hasta llegar justo, a dos barrancas que se unen a unos 15000 metros aproximadamente al Este del cráter, siguiendo después un solo cauce, el río Cantarranas, hasta los primeros manantiales, a 500 metros arriba del pueblo de San Baltasar Atlimeyaya, Ilamados De la Peña y Axomulco, en la margen derecha, y los del Ahuehuete en la izquierda, en donde empieza propiamente la corriente del Cantarranas, concluyendo éste en su convergencia con un río más grande, el Nexapa.

El agua sigue su cause hacia el Sur y es aprovechada por los pueblos, las fábricas, las plantas hidroeléctricas, las haciendas, los ranchos, el molino y la ciudad. En su recorrido recibe más volumen de agua del río de Tianguismanalco. Posteriormente, de dos manantiales más, el Chignahuapan o de Metepec y más adelante el de Axocopan. Cabe decir, que el tramo comprendido entre los primeros manantiales hasta su convergencia con el Nexapa, tiene una longitud de 17 kilómetros. En promedio, todo el aforo suma $2.389 \mathrm{~m}^{3}$ diarios, que durante los 365 días

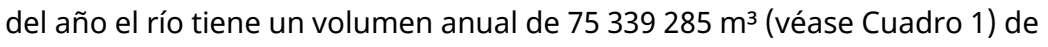
los cuales se aprovechaban $58,680,000 \mathrm{~m}^{3}$ anuales.

4 Voz alemana que significa "camino del valle" y es una línea que une los puntos de menor altura en un valle o en el cauce de un río y donde la corriente baja para convertirse en un (www.memidex.com/talwegs). 
Tabla 1. Capacidad del Río Cantarranas.

\begin{tabular}{|c|c|c|c|c|}
\hline \multicolumn{5}{|c|}{ Manantiales del Río Cantarranas } \\
\hline Aforos & $\begin{array}{l}\text { Metros } \\
\text { cúbicos } \\
\text { de agua }\end{array}$ & $\begin{array}{l}\text { Total de } \\
\text { aforo } \\
\text { diario }\end{array}$ & $\begin{array}{l}\text { Total de } \\
\text { aforo Anual }\end{array}$ & $\begin{array}{l}\text { Volumen del } \\
\text { aforo anual } \\
\text { aprovechado }\end{array}$ \\
\hline Manantiales De la Peña & $0.465 \mathrm{~m}^{3}$ & \multirow{6}{*}{ 2. $389 \mathrm{~m}^{3}$} & \multirow{6}{*}{$75339285 \mathrm{~m}^{3}$} & \multirow{6}{*}{$58,680000 \mathrm{~m}^{3}$} \\
\hline Manantiales de Axomulco & $0.290 \mathrm{~m}^{3}$ & & & \\
\hline $\begin{array}{l}\text { Manantiales del Ahuehuete y } \\
\text { demás inferiores }\end{array}$ & $0.865 \mathrm{~m}^{3}$ & & & \\
\hline $\begin{array}{l}\text { Río de Tianguismanalco, en su } \\
\text { confluencia con el Cantarranas }\end{array}$ & $0.135 \mathrm{~m}^{3}$ & & & \\
\hline $\begin{array}{l}\text { Manantiales de Metepec o } \\
\text { Chignahuapan }\end{array}$ & $0.284 \mathrm{~m}^{3}$ & & & \\
\hline Manantiales de Axocopan. & $0.349 \mathrm{~m}^{3}$ & & & \\
\hline
\end{tabular}

Fuente: Elaboración propia, basado en el Estudio de Reglamentación hecha por VI Zona de Puebla a los Ríos Cantarranas, Tianguismanalco y Manantiales de Axocopan de la Secretaría de Agricultura y Fomento (SAF), de la República Mexicana, Delegación de Aguas, Tierras y Colonización, Departamento Sur (Archivo Histórico del Agua; Aprovechamientos Superficiales; 4314; 57493; 1928; pp. 1-320).

A lo largo del cause se instalaron derivaciones que llevan el agua del río a todas las unidades productivas. Las derivaciones son presas o barreras construidas sobre el río, como desfiladeros, que tenían la finalidad de embalsar el agua para elevar su nivel con el objetivo de derivarla a los llamados aprovechamientos. Las derivaciones son 17, a su vez articuladas por 17 cajas partidoras, con 50 canales abiertos y cerrados, 7 tuberías, 1 acueducto elevado, 17 vasos de depósito, naturales y artificiales (o Jagüeyes), y 2 tanques de reposo. A partir de la primera derivación comienzan los aprovechamientos por parte de la industria y es la Fábrica de Metepec, propiedad de la Compañía Industrial de Atlixco S.A. (CIASA), la primera que toma el agua.

Esta primera derivación tiene dos compuertas en el centro para dejar paso al agua cuando necesitan hacer alguna reparación en el canal, con varios tramos para desarenar. Un canal de conducción sale de la margen izquierda y va a cielo abierto en partes y otras en túnel hasta llegar a la Planta Hidroeléctrica denominada de San Pedro, habiendo antes un vertedor que limita el gasto de agua. Sus dimensiones son de $1.80 \mathrm{mtrs}$. en la base inferior, 2.60 en la superior, 1.35 de altura y su desarrollo hasta la planta tiene un total de 1250.00 mtrs. La energía desarrollada en esta planta fue utilizada para mover la Fábrica de Hilados y Tejidos y Acabados de Algodón Metepec. El canal que conduce el agua a esta planta llega a un pequeño tanque para la decantación de las aguas, siendo desde allí 
entubadas hasta su entrada a la turbina. La cota del agua en el tanque de decantación es de 2,030,090 $\mathrm{m}^{3}$ y la de la descarga de 199,594 $\mathrm{m}^{3}$ de una caída de 34.15 para esta planta.
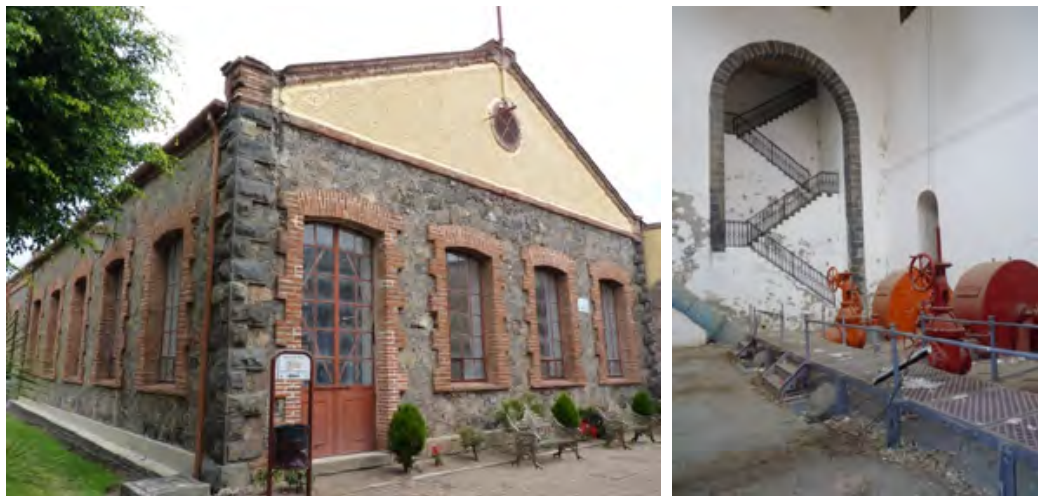

Ilustración 1. Sala de turbinas de la fábrica textil Metepec. Fotografía: Mariano Castellanos, 2013.

De la segunda derivación, ubicada en el pueblo de San Pedro Atlixco, a unos 600 mts. también llegaba el agua a la Planta de San Pedro, sólo que este canal la lleva a través de un túnel y después a cielo abierto hasta un pequeño tanque de decantación que se encuentra en el punto que se llama la "Casa blanca" el punto más elevado dentro del sistema hidráulico de la fábrica. De ahí baja el agua entubada hasta las turbinas que se hallan dentro de la Fábrica las cuales movían la maquinaria por medio de un sistema de cables y poleas adecuadas para este objetivo. La tubería tiene $1040 \mathrm{mtrs}$ de longitud hasta la entrada a las turbinas.

Antes de llegar a las turbinas se encuentra otro tanque de decantación y ahí arranca la línea de alimentación de las turbinas. Cabe destacar que la tubería al entrar al perímetro de la fábrica se bifurca en dos ramales, uno que va al Departamento de Acabados y otro que conduce el agua a la Sala de Turbinas, que se hallan en la parte central de la fábrica y mueve 3 turbinas. El desfogue de estas turbinas se hace por medio de un túnel que atraviesa toda la factoría, hasta otro tanque que se halla cercano a la Planta Hidroeléctrica de San Juan.

De la cuarta derivación, va a la Planta de San Juan, por medio de un túnel hasta llegar al tanque regulador en la entrada a las turbinas. Esta planta cuenta con dos turbinas de reacción, desde donde salen dos líneas de transmisión, una que conduce energía a la factoría con 285.00 mtrs. de extensión y la segunda con $\mathbf{4 1 5 . 0 0}$ mtrs. que da luz tanto a las dependencias de la negociación como al caserío de los operarios. En esta misma planta 
se deriva un canal también llamado de San Juan y llega hasta la fábrica y al caserío, además de ser abastecido por las aguas del Manantial de Metepec o Chinahuapan. La longitud del canal de San Juan es de 2500.00 mtrs, con una de caída 70 mtrs.

Tabla 2. Los aprovechamientos de las fábricas de Metepec.

\begin{tabular}{|c|c|c|c|c|c|c|c|c|}
\hline \multicolumn{9}{|c|}{ Los aprovechamientos de la Fábrica de Metepec } \\
\hline Derivación & $\begin{array}{l}\text { Aprovecha- } \\
\text { miento }\end{array}$ & Altura & $\begin{array}{l}\text { Litros por } \\
\text { segundo }\end{array}$ & $\begin{array}{c}\text { Volumen } \\
\text { Anual }\end{array}$ & $\begin{array}{l}\text { Metros } \\
\text { Cúbicos }\end{array}$ & H.P. & Husos & Telares \\
\hline $\begin{array}{l}\text { Primera } \\
\text { Derivación }\end{array}$ & $\begin{array}{c}\text { Caída de la } \\
\text { Planta de San } \\
\text { Pedro }\end{array}$ & $\begin{array}{l}34.15 \\
\text { mtrs }\end{array}$ & 1600 lps. & \multirow{4}{*}{$\begin{array}{c}365 \text { días, } \\
\text { las } 24 \\
\text { horas, } \\
100 \% \text { de } \\
\text { la toma }\end{array}$} & $\begin{array}{c}50,473.600 \\
M^{3}\end{array}$ & 750 H.P & \multirow{4}{*}{32888} & \multirow{4}{*}{1571} \\
\hline $\begin{array}{l}\text { Segunda } \\
\text { Derivación }\end{array}$ & $\begin{array}{c}\text { Caída de la } \\
\text { Planta Casa } \\
\text { Blanca }\end{array}$ & $\begin{array}{l}162.2 \\
\text { mtrs }\end{array}$ & 1573 lps. & & $\begin{array}{c}49,621,896 \\
M^{3}\end{array}$ & $\begin{array}{c}1925.96 \\
\text { H.P }\end{array}$ & & \\
\hline \multirow[b]{2}{*}{$\begin{array}{c}\text { Cuarta } \\
\text { Derivación }\end{array}$} & $\begin{array}{c}\text { Caída de la } \\
\text { Planta San } \\
\text { Juan }\end{array}$ & $\begin{array}{l}28.42 \\
\text { mtrs }\end{array}$ & 1573 Ips. & & $\begin{array}{c}49,621,896 \\
M^{3}\end{array}$ & $\begin{array}{c}361.43 \\
\text { H.P }\end{array}$ & & \\
\hline & $\begin{array}{l}\text { Caída de la } \\
\text { Planta de } \\
\text { San Juan a } \\
\text { la Fabrica y } \\
\text { caserío }\end{array}$ & $\begin{array}{c}70 \\
\text { mtrs }\end{array}$ & 300 lps. & & $\begin{array}{c}9,460,800 \\
M^{3}\end{array}$ & $\begin{array}{c}356.05 \\
\text { H.P }\end{array}$ & & \\
\hline
\end{tabular}

Fuente: Elaboración propia, basado en el Cuadro Descriptivo de los aprovechamientos de las aguas del Río Cantarranas y de sus afluentes el Tianguismanalco y los Manantiales de Axocopan (Sección: Departamento Jurídico; Serie Distribución de Aguas del Archivo Histórico del Museo Industrial de Metepec, BUAP; box 14, Exp. 2; 1930: 1).

Es fundamental hacer mención, que en 1898 un grupo de empresarios extranjeros y mexicanos -éstos con un menor peso-, fundaron la Compañía Industrial de Atlixco, S.A. la empresa más importante y grande de Atlixco. Algunos de ellos participaban, en el consejo de administración de la Fábrica de Papel San Rafael, en cuyo beneficio, y en el de la CIASA, conectaron una vía férrea que unía a las fábricas de ambas firmas con el gran mercado de la ciudad de México, formando para ello la Compañía de Ferrocarril de San Rafael y Atlixco, S. A. El español Luís Barroso Arias, representante y artífice de la CIASA, se asoció con otros de sus paisanos y algunos franceses para construir la factoría. Para tal afecto adquirieron las tierras de una hacienda llamada San Diego, con el fin de erigir allí su ambicioso proyecto. (Castañeda; 2001: 209)

Barroso se asoció con Agustín Garcin, de origen francés, quien a su vez era socio, entre otras empresas, de la Compañía Industrial Manufacturera, de Jalisco. Podría decirse que estos empresarios fueron quienes concibieron el proyecto original de la CIASA. Además de ser económicamente muy importantes, estos accionistas se aliaron con otros sobresalientes políticos 
y hombres de negocios; por ejemplo, con el vasco Antonio Basagoiti, quien fue el miembro más destacado de la CIASA, también accionista de la Compañía Fundidora de Fierro y Acero de Monterrey, S. A., accionista y miembro de la mesa directiva del Banco Nacional de México y presidentefundador del Banco Hispano Americano de Madrid. Eran tan ricos e influyentes que, en los años posteriores a la Revolución, estos industriales se mantuvieron y crearon importantes alianzas a través de la Cámara de Comercio, al tiempo que se aliaron, al inicio de los años 20, con el Partido Nacional Cooperativista. (Pacheco; 1984: 90-120)

La CIASA fue pues, por el poderío de sus principales accionistas, muy importante no sólo en el aspecto económico sino también político. Su Fábrica de Metepec por estar construida en el inicio del río es la que aprovecha primero el líquido, a pesar de ser la última en ser construida de todo el corredor hidráulico industrial. (Gamboa; 1985; 107) Le sigue la Fábrica de Hilados y Tejidos de Algodón El León. Inmediatamente después del desfogue a unos 800 mtrs. de las plantas de San Juan se encuentra la quinta derivación. Saliendo a la margen izquierda se encontraba un canal, en un tramo a cielo abierto y en partes en túnel, que antes de entrar a las turbinas tenía un tramo regulador de mayor acción que en su recorrido, en el cual se halla un vertedor lateral, que limita al gasto de la Fábrica. No era necesario aforar el canal de esta fábrica, ya que su gasto lo proporcionan los aprovechamientos de Metepec y lo que se derivaban es lo mismo que las plantas tercera y cuarta desfogaban.

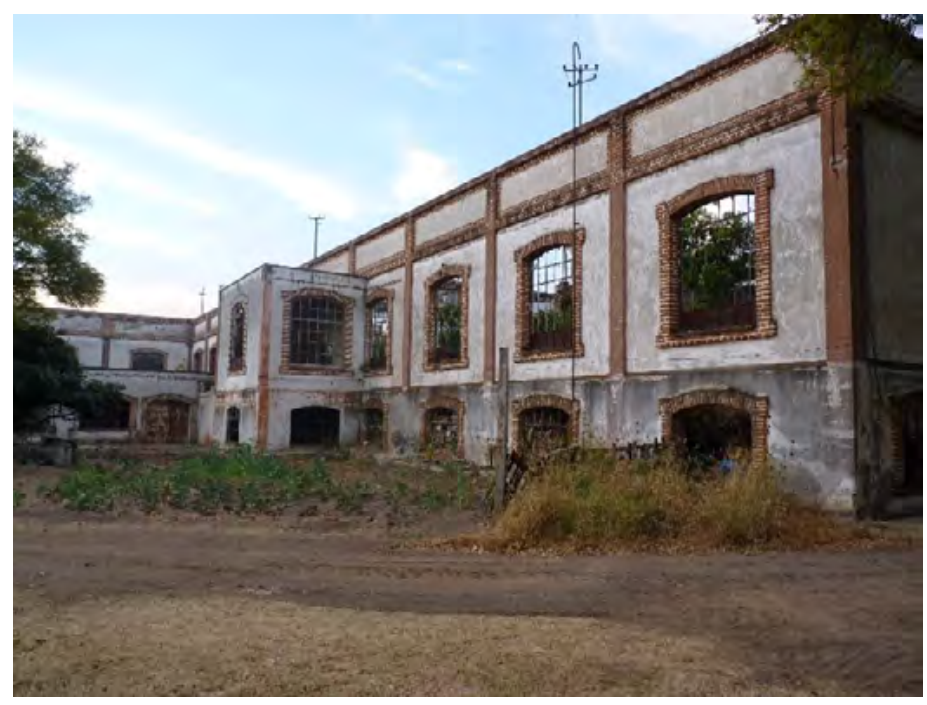

Ilustración 2. Fábrica El León. Fotografía: Mariano Castellanos, 2013. 
La longitud del canal desde la boca-toma hasta donde las aguas son entubadas es de $1241.00 \mathrm{mtrs}$. En la boca-toma tiene de cota de fondo 1986.07 mtrs., en el tramo regulador 1984.80 mtrs., con una caída aprovechable de 15.46 mtrs. Cabe decir que la potencia efectiva de su turbina es de un $75 \%$ y como la fuerza desarrollada no alcanzaba a mover toda la maquinaria, la fábrica tenía que comprar energía eléctrica a la Cia. Luz y Fuerza de Puebla, S.A., generada en las plantas de Portezuelo, ubicadas también en el valle de Atlixco.

Durante la segunda mitad del siglo XIX, aprovechando la política económica liberal que sostuvo el gobierno de México, en 1862 Eugenio Lions fundó en la ciudad de Puebla una tienda nombrada "La Ciudad de México", y posteriormente decidió dedicarse a la importación de telas. (Malpica y Patiño; 1987: CD Room) En 1897, junto con Adrián Reynaud y otros socios, formaron la compañía Lions Hermanos y se dieron a la tarea de construir su propia fábrica de hilados y tejidos de algodón. Al año siguiente consiguieron la concesión para generar fuerza motriz con las aguas del río San Baltasar, necesaria para mover la turbina de su fábrica. El mismo año el ayuntamiento aprobó construir una línea férrea de tracción animal entre Atlixco y la fábrica para transportar materiales de construcción, pasajeros y mercancías. Para 1899 la sociedad Lions Hermanos, que también poseía acciones de la Compañía Industrial de Orizaba S. A. (Veracruz), entre otras fábricas, abrió su nueva fábrica, El León, con 208 obreros. (Gamboa; 2001: 58)

Continuando con la descripción de los aprovechamientos de agua del Río Cantarranas, de la sexta derivación a la octava derivación existe una serie de aprovechamientos para los ranchos y las haciendas, la Ciudad de Atlixco y el Molino de San Mateo. Precisamente de la octava derivación el agua fue aprovechada por la Fábrica el Volcán. Esta factoría también aprovechaba las aguas de los Manantiales de Axocopan, con un canal general que lleva todo el volumen al río a unos los 650.000 mtrs. del manantial a la fábrica. Uno de sus aprovechamientos fue para la Presa La Concepción que lleva el agua a una Caja Partidora con dos vertedores laterales por donde salen el agua que aprovecha la fábrica. Estas aguas en un corto trayecto son entubadas para el paso del río, y ya en la otra margen, siguen por el canal a cielo abierto hasta ser nuevamente entubadas para entrar a una turbina. 


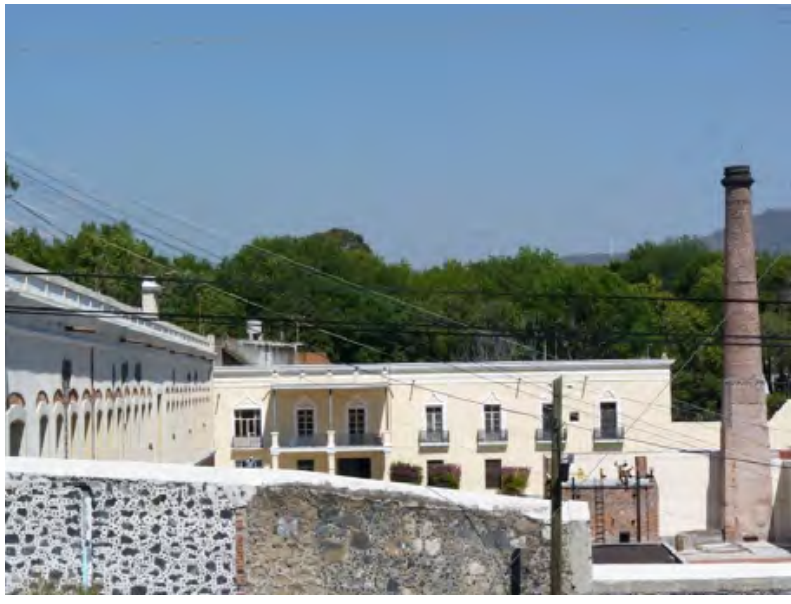

Ilustración 3. Fábrica El Volcán. Vista de la casa del administrador y chimenea. Fotografía: Mariano Castellanos, 2013.

La Fábrica del Volcán se construyó en 1891 por José Romano, José Villar Romano y Enrique Artasánchez quienes se asociaron para fundar "J. Romano y Compañía" dedicada originalmente al comercio. Seis años después compraron el molino El Volcán a Adrián Reynaud y a los Hermanos Lions, dueños de la fábrica El León, para producir textiles. Fue en 1902 cuando José Villar dejó la compañía y entraron Calixto Ramos y Antonio Pandal, pero se disolvió en 1907. Entonces Antonia Ajuria viuda de Romano, junto con Juan y Enrique Artasánchez, fundaron la sociedad "E. Artasánchez y Compañía" para continuar con el negocio (Malpica y Patiño; 1987: CD Room).

Ahora bien, en la Caja Partidora La Concepción, antes mencionada, uno de los vertedores se dirige a la Caja Partidora de La Carolina y ésta a su vez cuenta con una serie de vertedores, con diferentes aprovechamientos, entre estos el de la Fábrica de La Concepción, conectada a la novena derivación para generar fuerza motriz. Inmediatamente que sale de la caja entra a un jagüey de donde es conducida por medio de un canal de mampostería hasta el camino de Tochimilco, comunidad al sur de Atlixco. Cruza éste con un sifón y sigue en canal aéreo, sostenido por columnas de concreto hasta un punto de 200.00 mtrs de longitud, antes de la entrada a la turbina las aguas fueron entubadas. Al final del canal aéreo se encuentra un vertedor lateral cuyo paso se cierra cuándo la Fábrica se encuentra inactiva y toda el agua es derramada.

El jagüey sirve a esta factoría para almacenar el líquido en las horas que está inactiva, haciendo las veces de tanque regulador. Tiene una medida de, $70.00 \times 52.00 \times 1.25$ mtrs. dando una capacidad de almacenamiento de 
$4550 \mathrm{~m}^{3}$. Desde el jagüey la tubería baja verticalmente por el interior de una columna, siguiendo subterránea hasta entrar a la turbina. Esta turbina no podía mover toda la maquinaria de la Fábrica, teniendo que ayudarse con la producida por otras dos plantas, las de Gavito, también localizadas en el valle.

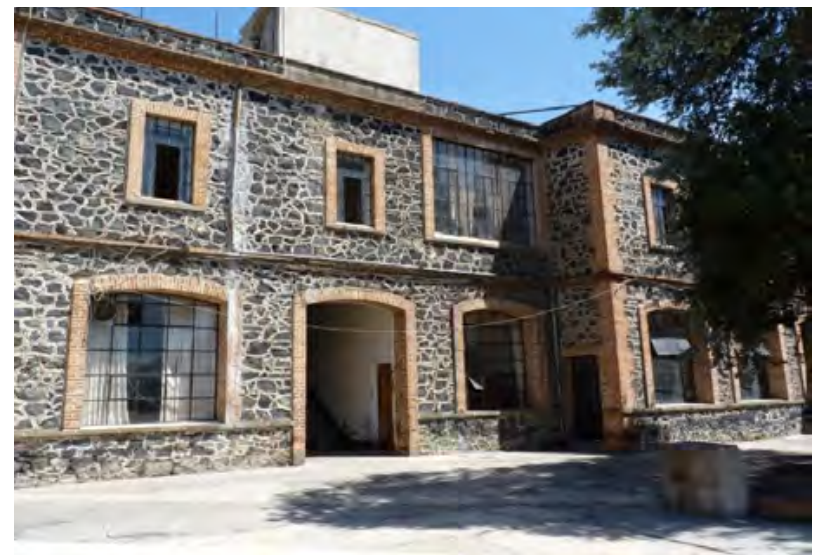

Ilustración 4. La fábrica La Concepción. Entrada principal vista desde el interior. Fotografía: Mariano Castellanos, 2013.

En cuanto a la fábrica La Concepción, cuyo último nombre comercial fue el de Fábrica Textil Comercial de Telas S.A., aunque siempre se le llamó "La Concha", se fundó en mayo de 1842. El Sr. Dionisio J. de Velasco, industrial textil y comisionista en el negocio de las importaciones, introdujo por el puerto de Veracruz máquinas cardadoras procedentes de Estados Unidos que fueron consignadas a José Antonio Serrano, propietario de la hacienda La Concepción. Es por ello que Serrano se convirtió en el dueño de la que se considera la primera fábrica textil del valle de Atlixco. El inmueble actual lo mandó a construir Ángel Díaz Rubín al final del siglo XIX. (Catálogo Nacional de Monumentos Históricos Inmuebles; 1988; 148)

Ahora bien, las aguas que desfoga la turbina de la Fábrica el Volcán, que devuelve al río, más las que derraman el vertedor de la Fábrica La Concepción, al juntarse en la Presa de la Carolina acumulan el suficiente líquido para abastecer a la fábrica de La Carolina. La toma es Ilevada por un canal a cielo abierto y en la margen izquierda es dirigida hasta la fábrica. Las instalaciones para esta unidad productiva son relativamente pequeñas en comparación con las otras factorías. Sólo tiene un canal que llega a un tanque regulador con un vertedor, que prácticamente es el que regulaba el gasto que entraba a la turbina por medio de una tubería. 


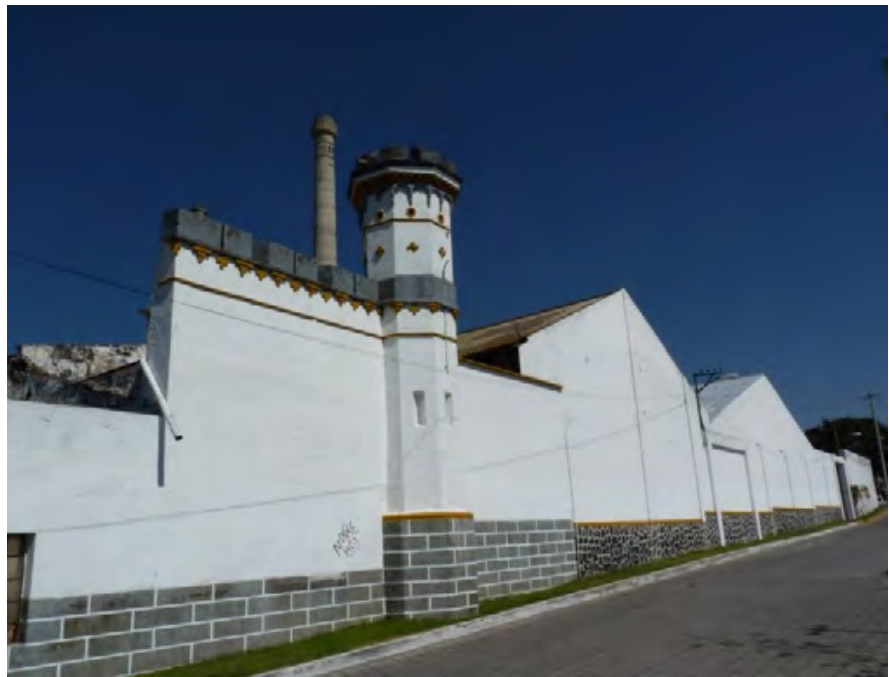

Ilustración 5. La fábrica La Carolina. Fachada lateral. Fotografía: Mariano Castellanos, 2013.

La Fábrica Carolina fue fundada por Manuel García Teruel hacia 1864, en las tierras del molino La Candelaria. En mayo de 1899 se asoció con las compañías "Sota y Compañía" y "Gavito y Compañía", constituyendo "Sota Gavito y Compañía". Posteriormente, en 1903 se reconstituyó la sociedad en "Gavito y Villar", y en 1908 se disolvió para convertirse en la firma "R. Gavito y Compañía". (Malpica, Patiño; Inédito: 1987). También, a finales del siglo XIX, en 1890 para ser precisos, Ángel Díaz Rubín también transformó su molino de trigo en la fábrica El Carmen, produciendo manta e hilaza y llegando a laborar en ella hasta 220 obreros. En esta pequeña factoría las relaciones obrero-patronales se fracturaron causando varios paros, aunque la verdadera lucha que experimentaron los obreros fue de carácter intergremial, contra los obreros de El Volcán (Malpica y Patiño; 1987: CD Room).

Para terminar, el último aprovechamiento industrial es el de la fábrica El Carmen. Las instalaciones hidráulicas de esta factoría también son pequeñas, que para mover sus turbinas recibió las aguas de dos tomas: primero de una presa especial que tenía la misma fábrica y luego de una parte del canal de desfogue de La Carolina. La presa representa la décimo primera derivación, además de que era aprovechada para el uso agrícola, sus aguas fueron para el Carmen y eran conducidas por medio de un canal de mampostería que tiene 527.20 mtrs. de longitud. De lado a lado se instalaron compuertas desarenadoras y al final del canal hay una Caja Partidora donde se divide el agua que entra a El Carmen y luego seguía para el riego. 


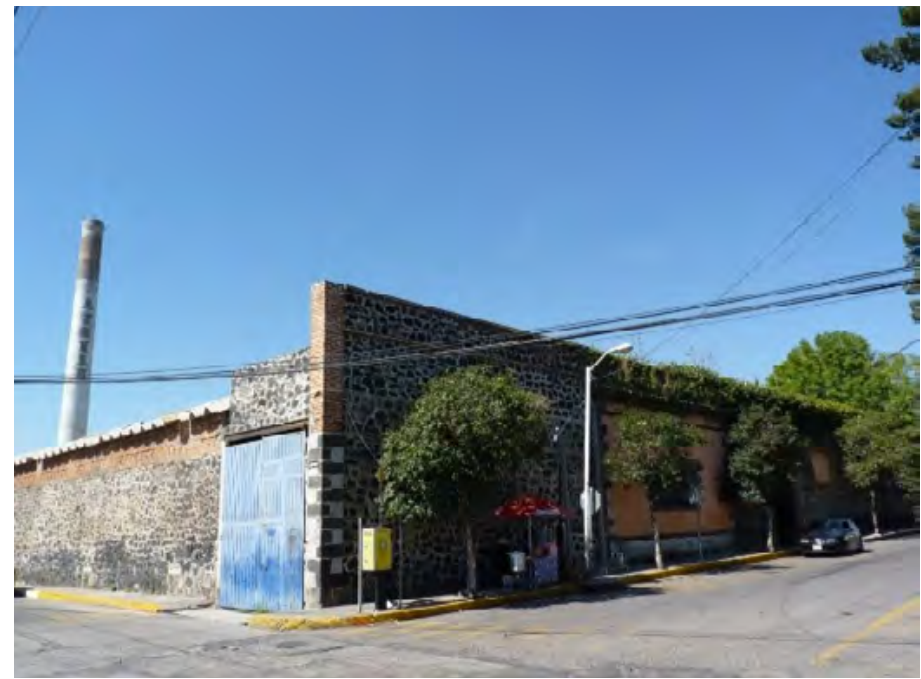

Ilustración 6. La fábrica El Carmen. Fachada principal.

Fotografía: Mariano Castellanos, 2013.

Tabla 3. Los aprovechamientos de las fábricas el León, el Volcán, la Concepción, la Carolina y el Carmen.

\begin{tabular}{|c|c|c|c|c|c|c|c|c|}
\hline \multicolumn{9}{|c|}{$\begin{array}{l}\text { Los aprovechamientos de las Fábricas: } \\
\text { el León, el Volcán, la Concepción, la Carolina y el Carmen. }\end{array}$} \\
\hline Derivación & $\begin{array}{l}\text { Aprovecha- } \\
\text { miento }\end{array}$ & Caída & $\begin{array}{l}\text { Litros } \\
\text { por } \\
\text { segundo }\end{array}$ & $\begin{array}{l}\text { Volumen } \\
\text { Anual }\end{array}$ & $\begin{array}{l}\text { Metros } \\
\text { Cúbicos }\end{array}$ & H.P & Husos & Telares \\
\hline $\begin{array}{l}\text { Quinta } \\
\text { Derivación }\end{array}$ & $\begin{array}{l}\text { Fábrica El } \\
\text { León }\end{array}$ & $\begin{array}{l}15.46 \\
\text { mtrs }\end{array}$ & 1800 lps. & $\begin{array}{l}365 \text { días, las } 24 \\
\text { horas, } 100 \% \text { de } \\
\text { la toma }\end{array}$ & $\begin{array}{c}56,764,800 \\
M^{3}\end{array}$ & $\begin{array}{l}285.46 \\
\text { H.P. }\end{array}$ & 6832 & 416 \\
\hline $\begin{array}{l}\text { Octava } \\
\text { Derivación }\end{array}$ & $\begin{array}{l}\text { Fábrica El } \\
\text { Volcán }\end{array}$ & $\begin{array}{l}16.32 \\
\text { mtrs }\end{array}$ & $\begin{array}{l}1102.9 \\
\text { Ips. }\end{array}$ & $\begin{array}{c}365 \text { días, las } 24 \\
\text { horas, } 77.99 \%\end{array}$ & $\begin{array}{c}34,781,055 \\
\mathrm{M}^{3}\end{array}$ & $\begin{array}{l}114.2 \\
\text { H.P. }\end{array}$ & 5096 & 250 \\
\hline \multirow[b]{2}{*}{$\begin{array}{c}\text { Novena } \\
\text { Derivación }\end{array}$} & $\begin{array}{l}\text { Fábrica La } \\
\text { Concepción }\end{array}$ & $\begin{array}{l}24.15 \\
\text { mtrs }\end{array}$ & $272.6 \mathrm{lps}$. & $\begin{array}{l}365 \text { días, las } 24 \\
\text { horas, } 85.65 \%\end{array}$ & $\begin{array}{c}8,596,714 \\
M^{3}\end{array}$ & $\begin{array}{l}119.5 \\
\text { H.P. }\end{array}$ & 8616 & 337 \\
\hline & $\begin{array}{l}\text { Fábrica La } \\
\text { Carolina }\end{array}$ & $\begin{array}{l}14.80 \\
\text { mtrs }\end{array}$ & $\begin{array}{l}1389.8 \\
\text { Ips. }\end{array}$ & $\begin{array}{c}365 \text { días, las } 24 \\
\text { horas, } 96.24 \% \\
\text { principalmente } \\
\text { del desfogue } \\
\text { del Volcán }\end{array}$ & $\begin{array}{c}34,781,055 \\
\mathrm{M}^{3}\end{array}$ & $\begin{array}{l}175.2 \\
\text { H.P. }\end{array}$ & $\begin{array}{c}\text { Sin } \\
\text { datos }\end{array}$ & $\begin{array}{c}\text { Sin } \\
\text { datos }\end{array}$ \\
\hline $\begin{array}{c}\text { Décimo } \\
\text { Primera } \\
\text { Derivación }\end{array}$ & $\begin{array}{l}\text { Fábrica El } \\
\text { Carmen }\end{array}$ & $\begin{array}{l}11.62 \\
\text { mtrs }\end{array}$ & $\begin{array}{l}1439.8 \\
\text { Ips }\end{array}$ & $\begin{array}{c}365 \text { días, las } 24 \\
\text { horas, } 100 \% \\
\text { del desfogue } \\
\text { de La Carolina }\end{array}$ & $\begin{array}{c}34,781,055 \\
\mathrm{M}^{3}\end{array}$ & $\begin{array}{l}144.6 \\
\text { H.P. }\end{array}$ & 6040 & 232 \\
\hline
\end{tabular}

Fuente: Elaboración propia, basado en el Cuadro Descriptivo de los aprovechamientos de las aguas del Río Cantarranas y de sus afluentes el Tianguismanalco y los Manantiales de Axocopan (Sección: Departamento Jurídico; Serie Distribución de Aguas del Archivo Histórico del Museo Industrial de Metepec, BUAP; box 14, Exp. 2; 1930: 1). 

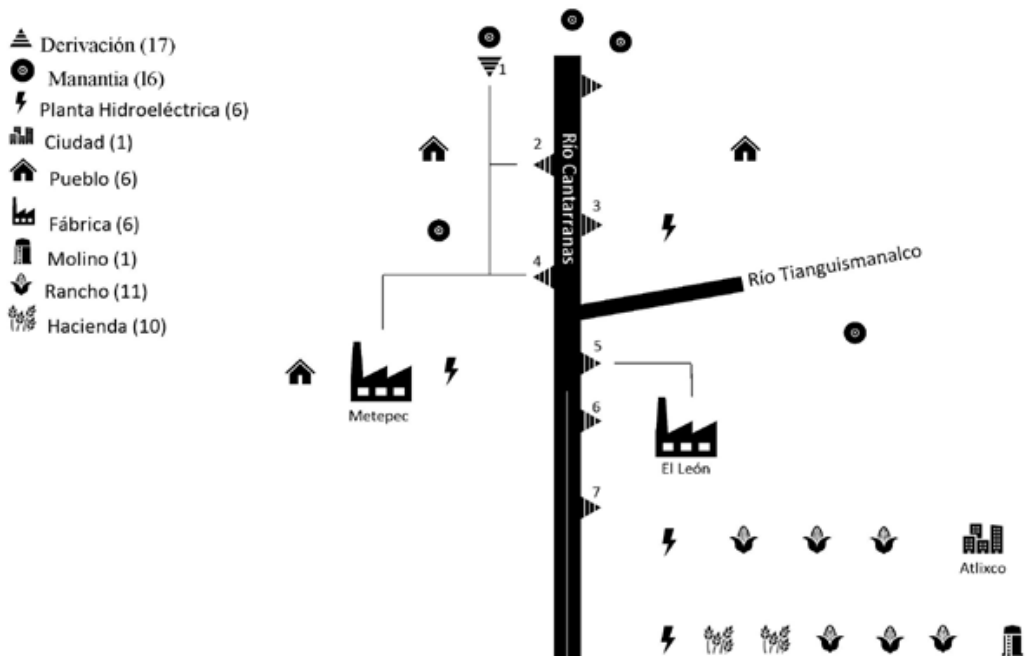

Margen Derecha

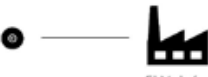

触<smiles>C1CCCCC1</smiles>

Af

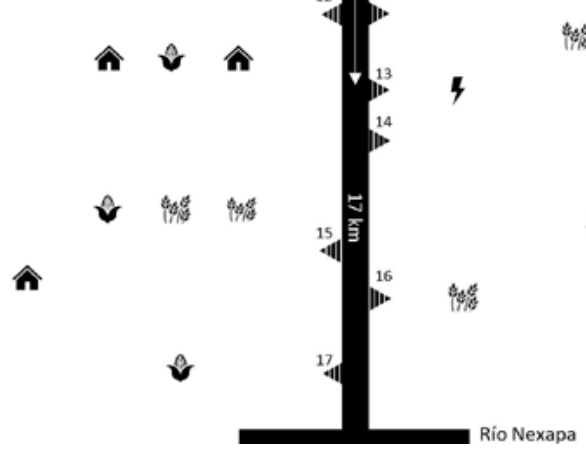

Margen Izquierda

Ilustración 7. Derivaciones, fábricas y otros aprovechamientos. Fuente: Elaboración propia, basado en Esquema del Estado de Puebla, desde su nacimiento hasta su confluencia con el Río Nexapa, con anotaciones de aprovechamientos, manantiales, estaciones de aforo, etc. Secretaría de Agricultura y Fomento, Dirección de Aguas, Tierras y Colonización, VII Zona. (Sección: Departamento Jurídico; Serie Distribución de Aguas del Archivo Histórico del Museo Industrial de Metepec, BUAP; box 14, Exp. 1; 1928: 1). 
Los aprovechamientos hidráulico-industriales de las fábricas textiles en torno al Río Cantarranas representan sólo una quinta parte de toda la infraestructura instalada. El impacto en el paisaje fue de grandes dimensiones. En primer lugar, la irrupción de grandes construcciones para albergar la maquinaria y todo el equipo para la producción de textiles; en segundo lugar, la llegada de trabajadores incrementó la población y en tercer lugar por el aumento en la demanda del líquido para el consumo doméstico. Todo ello tuvo consecuencias catastróficas para el medio ambiente, principalmente el uso de los diversos químicos, solventes y combustibles, usados tanto para los procesos productivos como para la generación de energía, rompieron con un ciclo en el uso del agua que llevaba siglos en cierto equilibrio.

Aunque contamos con éste gran patrimonio industrial, que representó un contexto económico de "prosperidad" y cambio en las estructurar laborales, tenemos aún algunas temas pendientes: el Río Cantarranas se encuentra en un estado grave de contaminación, los bienes de este patrimonio, en algunos casos están en el abandono, continúan los problemas ancestrales por el uso de los recursos acuíferos y el campo en la región está en proceso de abandono por falta de oportunidades laborales que traen como consecuencia la migración hacia las grandes ciudades y/o a los Estados Unidos. Por esta razón, considero que el patrimonio cultural, pueden ser el eje vertebrador de una gestión sustentable de los recursos culturales y naturales que nos lleve a una discusión, tanto en los procesos de planificación y ordenamiento territorial, así como la gestión del agua como el punto central. En cuanto al manejo de los recursos culturales del paisaje del agua, en importante tomar en cuenta que en los procesos de preservación del patrimonio es necesario generar un imaginario desde el presente con fundamento en la historia y con prospección hacia un mejor futuro para la región.

\section{Conclusiones.}

Para concluir, importante hacer la reflexión sobre la relación entre el paisaje y patrimonio cultural. Se debe decir que durante mucho tiempo el paisaje y el patrimonio se han presentado como conceptos antagónicos. El paisaje se ha definido en términos escénicos y visuales, como una imagen, algo observado, real o representado. El patrimonio, por su parte, en sus acepciones más habituales, edificios históricos, obras de arte o sitios arqueológicos, ahora también están incluidos en patrones de asentamiento y la historia, las costumbres y las formas de vida que han dado forma al paisaje actual. En este sentido pocos ven y discuten sobre la aportación positiva del patrimonio al paisaje, así como la idea de que el paisaje en sí mismo es un patrimonio. En este sentido, tal como se ha expresado de 
alguna manera en este trabajo, el patrimonio se puede definir como un proceso, no sólo como un producto; es decir, no como algo que es sino como algo que hace.

Podemos afirmar que estos dos conceptos están en convergencias. La diferencia entre el paisaje y el patrimonio no ha aportado cosas positivas ya que ha dejado de lado los aspectos más importantes y fundamentales de los dos conceptos. Al contrario, ha ocasionado la pérdida de centralidad subjetiva y perceptiva que por los dos conceptos tienen el elemento humano. Aunque el paisaje y el patrimonio tienen su propia materialidad no se trata de objetos sino un conjunto complejo de conceptos e ideas. Pero, esta división se está desdibujando porque de un lado y de otro de esta frontera imaginaria, se trabaja en la generación de una conciencia colectiva, tanto en la academia, en los gobiernos, como en la sociedad civil. Es decir, se están abriendo las puertas en el terreno del paisaje patrimonial y su multifuncionalidad en el ámbito de la gestión, como una herramienta de re-significación de los territorios y sus bienes culturales.

Ahora bien, en el caso del paisaje de agua en el valle de Atlixco, como patrimonio cultural, éste desempeña un papel protagonista tanto en su génesis como en su configuración actual como patrimonio, en su funcionamiento y en la percepción social y cultural del territorio. Más aún cuando existe un interés en aquellos paisajes en los cuales el agua constituye la estructura vertebradora de todo un sistema territorial, desde los cuales se han formado indisolubles redes de asentamientos, desde la instalación más pequeña hasta la construcción de una ciudad, con valor histórico-cultural-identitario.

Por esta razón es pertinente aclarar aquí, que el agua se convierte en el símbolo del paisaje y a la vez la conexión de las personas con la historia y el espacio. La manera como el agua de los ríos combinan y mezclan sus cursos, la vida natural y las actividades humanas, nos permiten "medir" el paso del tiempo, tanto en escala estacional con crecidas, sequías, reflujos y desbordamientos, hasta los aprovechamientos para la industria textil, el agua nos presenta una realidad del paisaje que va más allá de las definiciones tradicionales del paisaje esencialmente visual y se convierte en un punto de referencia de las personas, los lugares y los entornos, en una integración constante del pasado y del presente. Esta reflexión, comienza necesariamente por las personas y la sociedad, su historia y después por su entorno.

Es importante mencionar que en la valoración del paisaje del agua y la infraestructura industrial en Atlixco se concentran en dos niveles: el primero es la consideración de que el agua en su estado natural es patrimonio y el segundo es el complejo sistema hidráulico que hizo 
posible el aprovechamiento del líquido como el rico repertorio de bienes culturales. Ahora, el nivel de patrimonialización ligado al agua en sus múltiples manifestaciones materiales e inmateriales expresan una larga historia en el modelaje del entorno a partir de su utilización, ya que generan sentimientos de pertenencia fuertemente arraigados a la sociedad.

Es necesario considerar que el paisaje del agua es el que le da el carácter al territorio, como un hecho complejo e integrador de la materialidad, la percepción y la representación. El valor patrimonial corresponde al líquido, pero también al proceso de industrialización como un todo, con todos sus componentes los hidráulico-industriales, además los caminos las cosechas y las prácticas agrícolas, las construcciones propias del regadío, los pueblos y la ciudad, su población y sus prácticas culturales. Es decir, se trata de comprender las todas relaciones de los componentes del patrimonio en el paisaje.

Desde esta perspectiva, el paisaje del agua como bien cultural de Atlixco, requiere de una visión territorial renovada capaz de asumir tanto la complejidad del mismo concepto como la necesidad de la aplicación de una propuesta de análisis desde la transdicisplina, que vayan más allá de los limites geográficos, es decir debemos reflexionar sobre el concepto paisaje desde las diferentes definiciones, pasando por sus componentes históricos, sociales, culturales, económicos, hasta llegar a la defensa y protección como patrimonio para finalmente plantear oportunidades.

Es importante recalcar que los paisajes del agua, además de ser patrimonio, son un excelente indicador, tanto de la calidad del líquido, como de la calidad de vida de los habitantes que viven en éste. Los paisajes son el reflejo de salud del territorio y su sociedad, por ello es necesario el abordaje histórico de la configuración del patrimonio estructurado por el agua. En ente sentido, un paisaje patrimonial asimilado por la sociedad puede coadyuvar a elevada calidad de vida de la sociedad, porque nos ofrecen experiencias (estéticas, sensoriales o emotiva), y establece vínculos atávicos, afectivos y culturales. Por eso se insiste en que debemos ver el paisaje, el agua y el patrimonio que genera, más allá de las consideraciones visual, ya que tiene una carga simbólica que puede lograr construir una idea de bien cultural común. 


\section{Referencias.}

Archivo Histórico del Museo Industrial de Metepec-DIHMO-VIEP-BUAP.

Archivo Histórico del Agua-Conagua.

Bazant, Jan (1964) Evolución de la industria textil poblana (1544-1845), Vol. 13, Colegio de México, México.

Bethemont, J., Honegger-Rivère, A y Le Lay, Y. F. (2006) Les paysages des eaux douces". Géoconfluences. Le paysage dans tous ses états, 7, Francia.

Castañeda G., Ma. del Rocío (2001) Las vertientes de los ríos: modernización y conflicto social en Atlixco, Puebla. 1880-1920. Tesis de Doctorado en Historia, COLMEX, México.

178 Castañeda G., Ma. del Rocía (2005) Las aguas de Atlixco. Estado, haciendas, fábricas y pueblos, 1880-1920. CIESAS, México.

Castellanos, Mariano (2009) "El Agua, la energía y la producción textil en la fábrica de Metepec, 1898-1908" en Rosalva Loreto López (Coor.), Agua, poder Urbano y Metabolismo Social, BUAP, México.

Catálogo Nacional de Monumentos Históricos Inmuebles; Municipio de Atlixco Puebla. (1988) Centro Regional INAH, Puebla.

Chávez, C. y Trigo B. (coords) (2005) Programa de manejo para el Parque Nacional Iztaccihuatl- Popocatépetl. UAM, México.

Fernández, Federico y García Ángel J. (coords) (2006), Territorialidad y paisaje en el Altepetl del siglo XVI, FCE, México.

Gamboa O., Leticia (1985) Los empresarios de ayer. El grupo dominante en la industria textil de Puebla 1906-1929. UAP, México.

Gamboa Ojeda, Leticia (2001) La urdimbre y la trama. Historia social de los obreros textiles de Atlixco 1899-1924, FCE-BUAP, México.

Gamboa Leticia y Estrada Rosalina Urroz (1986) Empresas y Empresarios textiles de Puebla, Análisis de dos casos, UAP, México.

Garavaglia, Juan Carlos (1996) "Atlixco: el agua, los hombres y la tierra en un valle mexicano (siglos XIV-XVII)" en Alejandro Tortolero (Coord.) Tierra, agua y bosques. Historia y medio ambiente en el México central. Crentre Français d'Études Mexicaines et Centreamericaines, Instituto Mora, México.

Gómez, Cristina (1989) Puebla: lo obreros textiles en la revolución, UAP, México.

Lowenthal, David (1996) "Paysages et identiterés nationales", en Marcel Jollivet; Nicole Eyzner d'Europe ses campagnes, Institut d'Ëtudes Politiques, Francia.

Luna, F. (2011) Análisis multemporal de la dinámica en el cambio de uso del suelo rural-urbanoen la región de Atlixco, Puebla, tesis de doctorado, Colegio de Posgraduados, México.

Malpica, Samuel (1989) Atlixco: historia de la clase obrera, BUAP, México. 
Malpica, Samuel (2002) Metepec la máquina urbana, BUAP, México.

Malpica, Samuel e Patiño, Hilda (2004) Arqueología Industrial de Atlixco, ECUMBUAP (CD Room), México.

Mata Olmo, Rafael y Fernández Santiago (2008) Paisaje y patrimonios culturales del agua, Fundación Nueva Cultura del Agua, Panel Científico-técnico sobre Gestión del Agua, Convenio entre el Ministerio de Medio Ambiente y la Universidad de Sevilla, 2008, España.

Martínez de Pisón, Eduardo (2009) Miradas sobre el paisaje, Paisaje y Teoría, Biblioteca Nueva, España.

Mertens, Hans (1983) Atlixco y las haciendas durante el Porfiriato, Universidad Autónoma de Puebla, México.

Obregón, Gonzalo (1986) Monumentos de Atlixco, INAH, México.

Pacheco, Pilar (1984) Los empresarios de la Compañía Industrial de Atlixco, S.A., Tesis de licenciatura en Historia, UAP, México.

Paredes, Carlos (1991) La región de Atlixco, Huaquechula y Tochimilco. La sociedad y la agricultura en el siglo XVI, CIESAS, FCE, México.

Reyes, Rosalia Liboria y Sánchez, Andrés (2014) El paisaje como patrimonio natural y cultural. Benemérita Universidad Autónoma de Puebla, México.

Ribas, Anna (2006) “Naturaleza y cultura en la creación y valorización de los paisajes del agua" en VII Coloquio Ibérico sobre Planificación y Gestión del Agua celebrado, UAB, España.

Saurí, David (2001) “Natura, cultura i geografia des del món de les rieres mediterránies", Seminari interdisciplinar sobre l'aigua, Institut d'Estudis Catalans, Barcelona.

Tortolero, Alejandro (2006) El aguia y su historia. México y sus desafíos hacia el siglo XXI. Siglo XXI, México.

www.aurex.org

www.memidex.com 